\title{
Medical Error Reporting Attitudes of Healthcare Personnel, Barriers and Solutions: A Literature Review
}

\author{
Aysun Ünal ${ }^{1^{*}}$ and Seyda Seren ${ }^{2}$ \\ ${ }^{1}$ Department of Pediatric Surgery, Dokuz Eylul University, Izmir, Turkey \\ ${ }^{2}$ Department of Nursing Management, Dokuz Eylul University, Izmir, Turkey \\ *Corresponding author: Aysun Ünal, Department of Pediatric Surgery, Dokuz Eylul University Hospital, Izmir, Turkey, Tel: +90 532 697 18 67; E-mail: \\ aysun.unaldeu@gmail.com
}

Received date: November 30, 2016; Accepted date: December 14, 2016; Published date: December 22, 2016

Copyright: ( 2016 Ünal A, et al. This is an open-access article distributed under the terms of the Creative Commons Attribution License, which permits unrestricted use, distribution, and reproduction in any medium, provided the original author and source are credited

\begin{abstract}
Introduction: Medical error reporting has been recognized as the cornerstone of patient safety practices; however, healthcare personnel often do not report errors. In order to increase the frequency of error reporting, it is important to understand both the healthcare workers' attitudes towards reporting, as well as what they perceive as barriers.

Aim: The aim of this literature review was to identify the medical error reporting attitudes of healthcare personnel worldwide, as well as the barriers they encounter and their suggestions to increase reporting.

Methods: The national and international databases were scanned to identify the studies performed on medical error attitudes and barriers. A total of 28 studies that fit the criteria were evaluated.

Results: According to the studies that were analyzed, the most commonly encountered reporting barrier was the fear of individual and legal accusations among healthcare personnel. The personnel most frequently suggested using anonymous reporting systems, modifying the "accusation" culture and encouraging timely reporting in order to eliminate the reporting barriers.

Conclusion: This review provides up-to-date information on medical error reporting barriers, solution suggestions directed towards these barriers, and suggestions from healthcare personnel for an effective reporting system. It will guide healthcare providers, quality and risk management unit employees, administrators, and institutions that are trying to develop an effective reporting system toward quality patient care.
\end{abstract}

Keywords: Nursing; Medical errors; Error reporting barriers; Attitudes

\section{Introduction}

Although significant efforts are made to prevent errors within any system, errors take place in every environment related to humans [1]. In the Institute of Medicine's (IOM) report Human Error, it was indicated that "medical care may not be safe" and it was estimated that, in US hospitals, between 44,000 and 98,000 individuals die annually from medical errors. This number is greater than the number of deaths due to traffic accidents, breast cancer, or AIDS. Furthermore, the cost of medical errors is estimated to be between 37.6 and 50 billion dollars $[2,3]$. Following this report, worldwide health systems began to collaborate over the concept of "Patient Safety" and took action however, studies conducted recently show that there are still many practices that need to be applied. According to the IOM literature, an estimated number of 210,000 annual fatal medical errors (in an evidence based method) were related to preventable damages. The actual number of deaths related to preventable errors has been estimated to be 400,000 per year [4].

Patient safety requires careful organizational responsibility in order to prevent, identify, analyze and correct possible errors. All healthcare employees are responsible for preventing errors and identifying high risk situations, as well as reducing the dangers of high-risk situations and adverse events. In institutions where such an attitude exists, there also exists a patient safety culture $[5,6]$.

Error reporting is generally accepted as a basic initiative in improving patient safety [7], and the main purpose of error reporting systems is to learn from experience. Often, health service institutions and employees do not share what they learn from errors; as a result, the same errors repeatedly occur in different environments, and patients constantly encounter preventable damage [8]. Although there is a high demand for reporting, it is never sufficient. For example, in England, simple errors are reported at a rate of $22 \%-39 \%$, while more serious errors often go unreported [9].

There are many reasons for avoiding error reporting, including legal and institutional concerns, as well as personal guilt and regret. Other examples are damage to professional prestige, risk of job loss and fear of getting reprimanded or questioned [10,11]. These barriers substantially limit the monitoring of errors and improvement of patient safety [12]; therefore, it is difficult to establish an institutional or national error reporting system [13].

It has been emphasized that, in order to increase the efficiency of error reporting systems, these systems should be designed in such a 
Page 2 of 8

way that they can be used by multiple healthcare personnel (doctors, nurses, pharmacists, etc.) [14]. For this reason, it is very important to identify the barriers presented in the literature, as well as the suggestions of healthcare personnel with regard to these barriers, in order for healthcare personnel to develop a positive attitude towards reporting. This positive attitude can then be used to develop an effective reporting system that can be used by all healthcare personnel.

\section{Aim}

The aim of this literature review was to identify the medical error reporting attitudes of the world's healthcare personnel, the barriers they encounter and their suggestions for increasing error reporting.

\section{Literature review questions}

- What are the medical error reporting attitudes among healthcare personnel?

- What are the medical error reporting barriers of healthcare personnel?
- What are the suggestions of healthcare personnel for increasing medical error reporting?

\section{Methods}

\section{Search strategy}

A systematic review of the literature relating to medical errors, error reporting, error reporting barriers, and reporting systems in all countries was conducted in February of 2014. Studies that were published between 1999 and 2013 were scanned using the following search engines: Google Scholar, EBSCOhost Online Research Databases, Medline/PubMed, Turkish Medline, and Health Source: Nursing/Academic Edition, Academic Google and the Cochrane Databases (Table 1). The search strategy included all languages and all types of trials and studies. The references from eligible articles were also hand-searched in order to identify additional relevant papers.

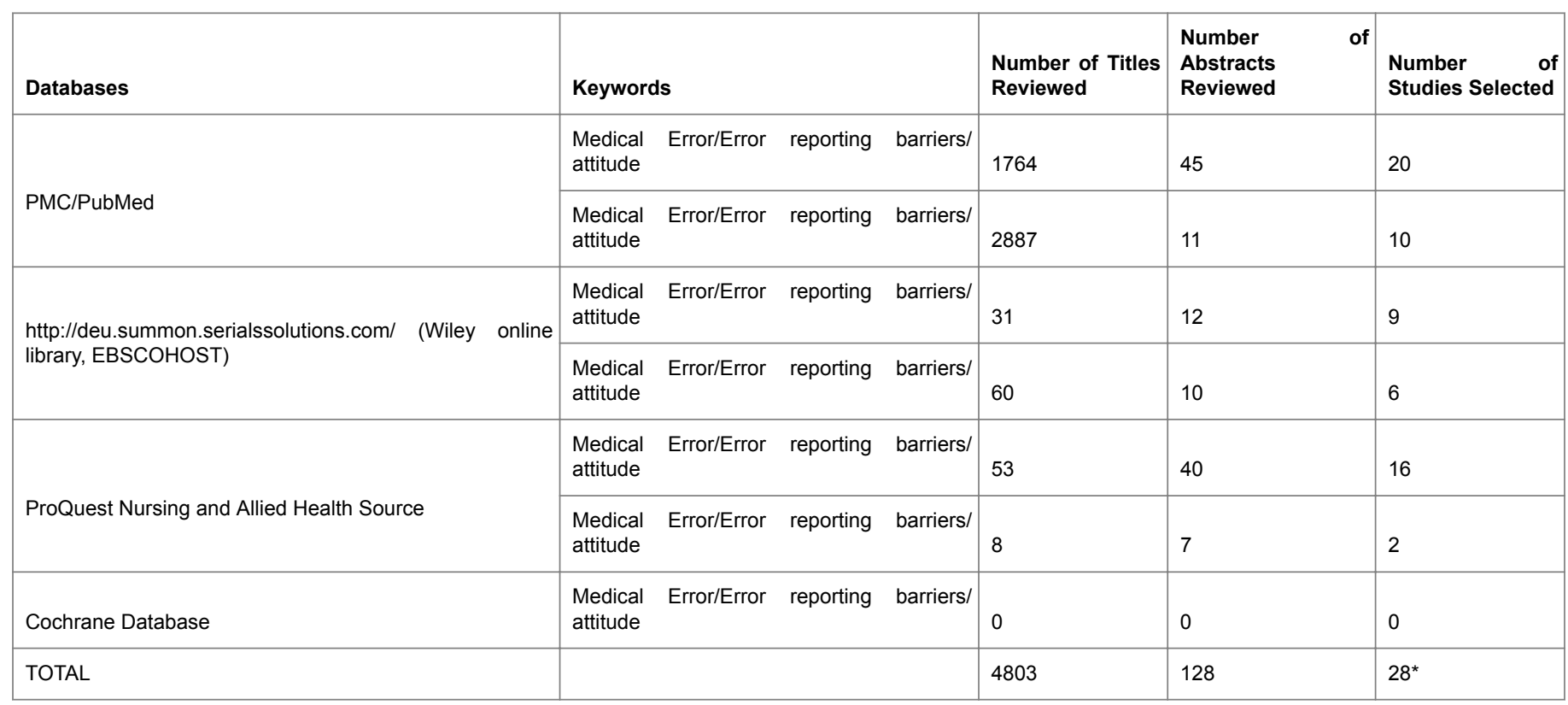

Table 1: Literature search and study selection, ${ }^{\star} \mathrm{A}$ total of 28 articles were included to the review since studies were present in multiple databases.

\section{Search terms}

The following keywords were used as search terms: medical error(s), error reporting barrier(s), attitude(s), physician(s), pharmacist(s) and nurse(s) (in English). Each of these keywords were combined using "or" then combining it with "and."

\section{Review procedure}

Each of the studies was conducted in different countries using different definitions, different types of trials, and different methods to collect the data. Therefore, we did not try to analyze the data from a statistical point of view, but the results were summarized according to the error reporting barriers, medical error reporting attitudes of the healthcare personnel, and their suggestions for increasing reporting.

\section{Article selection criteria}

\section{Inclusion/exclusion criteria}

We included all types of studies, for example, randomized controlled trials, non-randomized controlled trials, longitudinal studies, cohort or case-control studies and descriptive and qualitative studies. Full-text studies conducted on healthcare personnel that included error reporting attitudes, barriers and healthcare personnel suggestions for medical error reporting were selected for the sample group. Studies that investigated medical error rates, whose samples included students or employees working in clinics or studies that were conducted outside clinics (e.g. radiation oncology, pharmacology, etc.), were excluded from the sample. In addition, we excluded reviews, letters, conference papers, opinions, reports and editorial papers. 
Page 3 of 8

\section{Results}

\section{Features of the studies}

A total of 4,806 studies were screened by their titles and 4,678 titles were excluded based on the fact that they were not related to the topic, or that they were letters, editorials or reports. Therefore, 128 article abstracts were considered, after the title evaluation; 61 articles were evaluated for full text suitability and 67 studies were excluded because the samples were students or employees working in clinical units or studies that were conducted outside the clinic (e.g. radiation oncology, pharmacology, etc.). After the evaluation, 28 studies were further analyzed, while the other 33 studies were not considered based on the exclusion criteria (Figure 1).

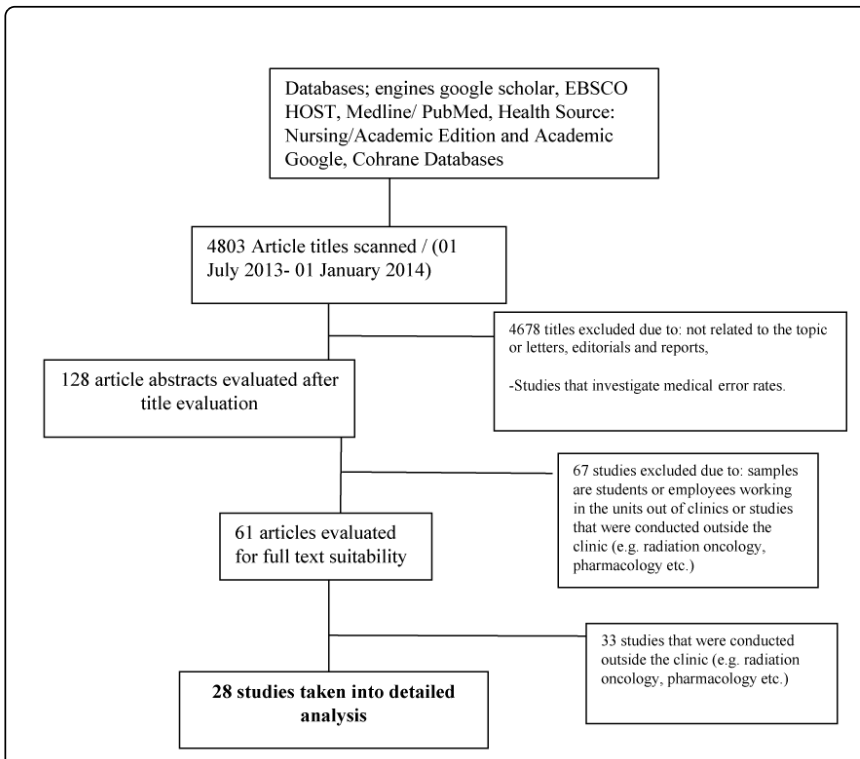

Figure 1: Literature review design.

The studies included in this literature review were those that were descriptive and qualitative and that investigated the medical error reporting attitudes and barriers of the healthcare personnel. When the methods of the studies were reviewed, 12 studies were descriptive, 4 studies were cross-sectional, 9 studies were qualitative and 3 studies were both qualitative and quantitative.

\section{Medical error reporting attitudes among healthcare personnel}

It was determined that, among all healthcare personnel, nurses reported more and knew more about the reporting system, when compared to the other healthcare personnel [15-17]. However, physicians were found to be the most reluctant when it came to reporting negative errors [16-19]. The employees tended to have the habit of instantly reporting falling, outcomes that required corrective treatment (such as medication errors), and errors that were witnessed. However, near-miss errors or errors that showed signs over time (Deep-vein thrombosis that developed due to insufficient prophylaxis, pressure ulcers, etc.) had a lower reporting rate. Since these errors occurred over time, they were considered to be complications due to prolonged hospitalization [16].

The type and severity of medical errors are perceived differently among healthcare professionals in those studies where the classifications of medical errors, according to their severity and outcomes, were examined. Nurses and pharmacists reported every type of error at a higher rate, regardless of the patient outcomes; whereas physicians reported errors with more serious outcomes at a higher rate [20]. Moreover, physicians were less likely to report near misses or lessserious patient outcomes, and a more limited proportion of their errors, when compared to the nurses $[16,20]$. However, the physicians classified the errors as errors at higher percentages when compared to the nurses [17]. In the literature, it was determined that more reporting was made when the outcomes of the errors were at the level of serious damage; in parallel, those errors with possible outcomes of no damage, or milder damage, were reported at a lower rate [15,21-24]. Although, the nurses did report errors that were committed by someone else in the team at a higher rate, when compared to the physicians (Table 2) [18].

\begin{tabular}{|c|c|c|c|}
\hline References & Personnel involved/Setting & Method & Attitudes and Barriers to Medical Error Reporting \\
\hline [25] & $\begin{array}{l}56 \text { physicians and } 66 \text { nurses/University } \\
\text { hospital }\end{array}$ & $\begin{array}{l}\text { Qualitative; nominal } \text { group } \\
\text { technique } \\
\text { Quantitative; descriptive } \\
\text { design }\end{array}$ & $\begin{array}{l}\text { Barriers for physicians; not knowing the usefulness of the } \\
\text { report, workload, the lack of information on how to report an } \\
\text { error, thinking that reporting has little contribution for } \\
\text { improvement of quality of care.Barriers for nurses; time } \\
\text { involved in documenting an error, is not anonymous, extra work } \\
\text { involved in reporting, hesitancy regarding "telling" on somebady } \\
\text { else, it is unnecessary to report the error and fear of lawsuits. }\end{array}$ \\
\hline [19] & $\begin{array}{l}315 \text { participants were doctors, nurses, } \\
\text { and midwives/three English NHS }\end{array}$ & Descriptive: survey design & $\begin{array}{l}\text { Healthcare professionals are in general, reluctant to report } \\
\text { behaviour. Doctors are less likely than nurses or midwives to } \\
\text { report colleagues. }\end{array}$ \\
\hline [26] & 15 physicians/Acute hospital & $\begin{array}{l}\text { Qualitative;semi-structured } \\
\text { interviews }\end{array}$ & $\begin{array}{l}\text { Take time to fill in reporting forms, lack of feedback and lack of } \\
\text { training about error reporting. }\end{array}$ \\
\hline [18] & $\begin{array}{l}74 \text { doctors, } 66 \text { nurses/Children's } \\
\text { Hospital }\end{array}$ & Descriptive; survey design, & $\begin{array}{l}\text { Perception of whether the exact error events and blamed the } \\
\text { concerns. }\end{array}$ \\
\hline
\end{tabular}


Citation: Ünal A, Seren S (2016) Medical Error Reporting Attitudes of Healthcare Personnel, Barriers and Solutions: A Literature Review. J Nurs Care 5: 377. doi:10.4172/2167-1168.1000377

Page 4 of 8

\begin{tabular}{|c|c|c|c|}
\hline [27] & $\begin{array}{l}3 \text { senior medical representatives and } 25 \\
\text { specialist physicians District General } \\
\text { Hospital }\end{array}$ & $\begin{array}{l}\text { Qualitative } \quad \text { semi-structured } \\
\text { interviews }\end{array}$ & Blame culture, the most important barrier is reporting. \\
\hline [28] & 30 physicians/University Hospital & $\begin{array}{l}\text { Descriptive; One group pre-post } \\
\text { test study }\end{array}$ & $\begin{array}{l}\text { Time constraints, the reporting process to disrupt work } \\
\text { processes, extra paper work, worries about career and their } \\
\text { personal reputations, is not sufficient incentives for reporting. }\end{array}$ \\
\hline [14] & $\begin{array}{l}\text { Eight physicians and six clinical } \\
\text { assistant/University Hospital }\end{array}$ & $\begin{array}{l}\text { Qualitative; focus group } \\
\text { interviews }\end{array}$ & $\begin{array}{l}\text { Long reporting process and personal factors (personal } \\
\text { perceptions regarding the importance of error reporting) are } \\
\text { determined barriers }\end{array}$ \\
\hline [16] & $\begin{array}{l}186 \text { doctors and } 587 \text { nurses/Various } \\
\text { Hospitals }\end{array}$ & $\begin{array}{l}\text { Descriptive; } \quad \text { cross-sectional } \\
\text { survey }\end{array}$ & $\begin{array}{l}\text { For doctors were lack of feedback, the incident form taking too } \\
\text { long to complete and a belief that the incident was unimportant. } \\
\text { Major barriers to reporting for nurses were lack of feedback a } \\
\text { belief that there was no point in reporting near misses and } \\
\text { forgetting to make a report when the ward is busy. }\end{array}$ \\
\hline [17] & $\begin{array}{l}40 \text { physicians, 26 } \\
\text { emergency medical } \\
\text { Emergency clinics }\end{array}$ & Descriptive;cross-sectional study & $\begin{array}{l}\text { Physicians were the least likely to report the error. For all } \\
\text { groups and error types, identification, disclosure, and reporting } \\
\text { increased with increasing severity. }\end{array}$ \\
\hline [29] & 597 nurses/University Hospital & $\begin{array}{l}\text { Descriptive cross-sectional, } \\
\text { correlational design }\end{array}$ & $\begin{array}{l}\text { Reporting barriers in order of importance; fear of management } \\
\text { and lack of sufficient time for reporting, documentation and } \\
\text { interdisciplinary communications failure and concerned about } \\
\text { colleagues. }\end{array}$ \\
\hline [24] & 799 nurses/Various hospitals & $\begin{array}{l}\text { Comparative descriptive survey } \\
\text { design }\end{array}$ & Exposure to disciplinary action and the fear of losing their jobs. \\
\hline [29] & 886 nurse/Training hospital & Descriptive; correlational study & $\begin{array}{l}\text { Punitive culture and concerned about of errors is kept in their } \\
\text { files }\end{array}$ \\
\hline [30] & 61 nurse/Medical Center & Descriptive; survey design & $\begin{array}{l}\text { Descriptive indicated in barriers; fear of the reaction they would } \\
\text { receive from the nurse manager and their peers }\end{array}$ \\
\hline [15] & $\begin{array}{l}55 \text { physicians and } 82 \text { nurses/Training } \\
\text { Hospital }\end{array}$ & $\begin{array}{l}\text { Descriptive; anonymous web- } \\
\text { based questionnaire survey }\end{array}$ & $\begin{array}{l}\text { Reporting take long and lack of time fear of legal action and } \\
\text { discussion and reporting does not contribute to the quality of } \\
\text { care is the idea that. }\end{array}$ \\
\hline [31] & $\begin{array}{l}22 \text { people consisting of doctors and } \\
\text { nurses/teaching Hospitals }\end{array}$ & $\begin{array}{l}\text { Qualitative; focus } \text { group } \\
\text { interviews }\end{array}$ & $\begin{array}{l}\text { Lack of a culture that encourages reporting and therefore, } \\
\text { negative perception and attitudes towards reporting, lack of } \\
\text { ability to report. }\end{array}$ \\
\hline [20] & $\begin{array}{l}18 \text { physicians, } 22 \text { nurses, } 16 \\
\text { pharmacists/Third level referral hospital }\end{array}$ & $\begin{array}{l}\text { Descriptive; a questionnaire using } \\
\text { two different clinical scenarios }\end{array}$ & $\begin{array}{l}\text { the type and severity of medication error influence healthcare } \\
\text { professionals differently. Nurses and pharmacists were likely to } \\
\text { report all medication errors, doctors were only likely to report } \\
\text { an error that resulted in an adverse outcome. }\end{array}$ \\
\hline [22] & 37 nurses/Intensive care units & \begin{tabular}{lr} 
Qualitative; & \multicolumn{2}{c}{ semi-structured } \\
questions & with $\quad$ individual \\
interviews &
\end{tabular} & $\begin{array}{l}\text { Lack of time, fear and lack of management feedback. When the } \\
\text { patient wasn't harmed nurses dont prefer to do reporting. }\end{array}$ \\
\hline [21] & 430 nurses/Hospitals in various regions & $\begin{array}{l}\text { Descriptive; A self-administered } \\
\text { survey }\end{array}$ & $\begin{array}{l}\text { Incidents were reported more frequently when the potential } \\
\text { consequences were considered severe for the patient. when } \\
\text { nurses and safety managers on wards discuss incidents and } \\
\text { their root causes, nurses feel less afraid of incident reporting. }\end{array}$ \\
\hline [32] & 38 nurse/State hospital & Descriptive & $\begin{array}{l}\text { Fear, manager of response, not know that the importance of } \\
\text { reporting and the event is not perceived as an error. }\end{array}$ \\
\hline [33] & 62 nurses/University hospital & Descriptive; survey design & $\begin{array}{l}\text { The most important factor in nursing management responses, } \\
\text { another factor is the feeling of fear of legal action as a result of } \\
\text { reporting. }\end{array}$ \\
\hline [34] & $\begin{array}{l}\text { Nine doctors, } 14 \text { nurses, seven } \\
\text { pharmacists/Four community hospitals } \\
\text { in Nova Scotia, Canada. }\end{array}$ & $\begin{array}{l}\text { Qualitative; } \\
\text { interviews }\end{array}$ & $\begin{array}{l}\text { Barriers to medication error reporting were thematised five } \\
\text { categories: reporter workload, Professional identity, information } \\
\text { gap, organisational factors and fear. Facilitators to encourage } \\
\text { medication error reporting were classified three categories: } \\
\text { reducing reporter workload, closing the communication gap } \\
\text { and educating }\end{array}$ \\
\hline
\end{tabular}




\begin{tabular}{|c|c|c|c|}
\hline [23] & 733 nurses/University hospital & Descriptive; survey design & $\begin{array}{l}\text { Blame and fear of punishment in addition nurses identified no } \\
\text { need to report if no harm to patient. }\end{array}$ \\
\hline [35] & 1180 Nurse/Nursing Homes & $\begin{array}{l}\text { Descriptive; cross sectional } \\
\text { design }\end{array}$ & $\begin{array}{l}\text { Risk of being harmed to confidence in the competencies and } \\
\text { reporting is difficult for nurses }\end{array}$ \\
\hline [36] & 433 anesthesiologist/Various hospitals & $\begin{array}{l}\text { Descriptive; self-administered, } \\
\text { mailed survey }\end{array}$ & The barrier of being concerned about blame by colleagues. \\
\hline [37] & 115 nurse/University hospital & $\begin{array}{l}\text { Qualitative; focus } \text { group } \\
\text { interviews }\end{array}$ & $\begin{array}{l}\text { Fear of legal procedures, threats of job, fear of losing } \\
\text { respectability, lack of information, lack of skills to error } \\
\text { management,unwillingness to accept responsibility for errors, } \\
\text { and the manager's response is inappropriate. }\end{array}$ \\
\hline [38] & 30 nurse/Private and tertiary hospitals & $\begin{array}{l}\text { Qualitative; (in-depth interviews) } \\
\text { and descriptive survey design }\end{array}$ & $\begin{array}{l}\text { barriers identified in the questionnaire; lack of training in } \\
\text { reporting system, workload, lack of access to computers, the } \\
\text { fear of being monitored, reporting of the form very detailed. }\end{array}$ \\
\hline
\end{tabular}

Table 2: Medical error reporting barriers and attitudes towards researches.

In the studies of the characteristics of professional groups, the educational backgrounds and cultural structures specific to their profession and existing complex organizations affected the attitudes toward reporting $[16,18,19,34]$. Accordingly, the nurses feared the administration more than the doctors [21,29], but the physicians' attitudes toward medical error reporting adversely affected that medical indemnity insurance for the hospital risk managers and lawyers. In addition, abstractions by colleagues' fears of criticism after making an error were also important factors, because their training to strive for an error-free practice and their cultures are not suitable for this $[16,36]$, from the perspective of pharmacists with a better position to identify the causes of medication errors [34]. However, studies have been addressed with regard to all professionals, generally, and specific information regarding pharmacists was rarely encountered.

\section{Medical error reporting barriers among healthcare personnel}

The fear of individual and legal accusation has been determined to be the most frequently encountered reporting obstacle in the studies included in this literature review $[15,18,20,23,24,29,30,32,33,35,36,39,40]$. Particularly, in studies conducted on nurses, the fear of individual accusation and administrator reactions took the place at the top of the list of obstacles $[23,29,32,33,35]$. Other reporting barriers among nurses, in the order of significance, were found to be: being thought of as incompetent, patients' negative attitudes, the stigma of incompetence, unsupportive work environment, long reporting process, the idea that reporting errors that do not damage the patient is unnecessary, not knowing the importance of error reporting, and lack of education, lack of feedback on reporting and not perceiving the error as an error [22,23,29,32,37,38].

In those studies conducted with physicians only, the lengthy reporting process, as well as the additional workload associated with reporting errors, was found to be two of the leading error reporting barriers. Other barriers that were determined, in order of significance, were the lack of feedback and discipline procedures regarding the error $[14,26,28]$. In these three studies, it was accepted by the physicians that reporting was unnecessary, and that the errors were usually "inevitable". Moreover, according to two additional studies, medical error reporting was considered potentially unmanageable and "meaningless" [16,27]. In studies involving physicians and other healthcare personnel, the type of damage and severity of the error, education level and occupation of the healthcare personnel, negative attitude towards reporting, lack of an encouraging culture in the institutions, and lack of reporting perception/education all affected the reporting rate (Table 2$)[15,18,20,28,31]$.

\section{Suggestions by healthcare personnel to increase medical error reporting}

The factors that were analyzed in order to increase the medical error reporting rate of healthcare personnel were presented most often in the qualitative studies [14,37,34]. Increasing the nurses' knowledge, ability, undertaking, and accountability aspects, encouraging a scientific environment, an anonymous reporting system and lack of authority [37], clinicians and administrators learning from their mistakes, patient education, determining the basic ethical duties for reporting and encouraging the employees [14] were all leading motivational factors for error reporting.

In a study conducted with focus group interviews, the factors that facilitated error reporting were themed into three groups: preventing a communication gap after reporting, education for success, and decreasing the workload while reporting. The participants stated that they could report more often if they received sufficient education on reporting, timely feedback, and if the reporting process was simplified [34]. In a study in which the suggestions of the healthcare personnel were examined in order to increase the degree of reporting, it was determined that the necessity of education towards errors that should be reported, regular feedback about errors, and the development of an evidence based system change medical error reporting in an electronic environment [18]. In a study in which the simplifying factors for medication error reporting were investigated, the use of an anonymous reporting system, removal of a fear atmosphere from the institution, simplification of the reporting procedure, and the establishment of the perception that reporting is beneficial were recommended $[23,31,41]$. In Jee-In Hwang et al.s study, the development of reward systems was the top priority implementation suggested by nurses to encourage error reporting [41].

In a study that determined the attempts to strengthen nurses reporting habits, the understanding and encouraging attitude of physicians and inspection authorities, identification of medication errors by the active participation of clinical nurses and clinical expert nurses, immediate reporting by the nursing administrator, sufficient time for reporting, and presence of nurse administrators to monitor 
the nurses who frequently commit errors with consistent disciplinary action were all specified [39].

\section{Discussion}

The reporting of medical errors is the focal point of the effort for reducing the incidence of these errors. The evaluation of the types and frequency of errors, and their effects on patients, have critical importance in the determination of the root causes of errors, and for the development of attempts toward the reduction and prevention of these errors [42,43]. Despite the critical importance of error reporting, healthcare professionals do not sufficiently report errors due to specific barriers.

It has been determined in studies that investigate the attitudes and perceptions towards medical error reporting that more reporting is done when the outcomes of the errors are at the level of severe damage; in parallel with this, less reporting is done when the potential outcome is harmless or only slightly harmful $[21,22]$. The types and severity of medical errors are perceived differently among healthcare professionals [17]. However, despite a common terminology related to the severity, types and outcomes of errors having been developed by international patient safety authorities, it was seen that this terminology is still not used and conceptualized as basic information by healthcare professionals.

When the error reporting barriers of healthcare personnel were investigated, the most commonly encountered obstacles were determined to be the fear of individual/legal accusation, and the fear of negative reactions from administrators and colleagues $[15,20,23,24,32,33,35,36,39,40]$. When the chronology of the studies was examined, a similar culture of fear seemed to be precedent in recent studies. Consequently, it was seen that, first of all, the fear obstacle toward medical error reporting remains and the strategies that have been developed are still insufficient.

The long duration of the reporting process, the belief that reporting errors that are not harmful to the patient is unnecessary and meaningless, the type of harm and severity of the error, lack of education, lack of feedback about reporting, the fact that the error is not perceived as an error, and lack of knowledge about the importance of error reporting were found to be other reporting barriers, determined in order of priority $[16,23,27,29,32,37]$. These determined barriers show the necessity for the development of health care personnel awareness about error types and severity, reportable errors and the importance of reporting.

Some suggestions have been offered to increase medical error reporting, in order to motivate and reinforce healthcare personnel in this direction. When these suggestions were evaluated in order of priority, education and the development of awareness about reporting, dissolution of the atmosphere of fear and potential risks as a consequence of reporting, delivery of constructive feedback in a reasonable amount of time, shortening of the reporting duration, and development of strategies to encourage reporting by administrators emerged $[18,23,39,31,34]$. Based on the results of these studies, the education of healthcare personnel with regard to error reporting has been proceeding, while the development of administrative strategies (positive feedback, absence of disciplinary action, etc.) is still required. The feedback of reporting has been seen as an important issue that requires emphasis. According to the results of this literature review, the identification of the feedback forms used in error reporting, and the best application suggestions in this field, including a safe feedback loop in institutions, the use of effective feedback channels, supply of feedback about the analysis of reporting, and the results and corrective actions (in a timely manner), were considered to be the best applications. In this study, institutions were recommended to create forms and systems that included the best applications with regard to effective feedback [44].

In several studies, it was observed that the investigated preferences of healthcare personnel with regard to the type of error reporting system and their thoughts about the use of different systems were few. In one study, the thoughts and suggestions of the physicians and nurses about the features of the error reporting system were investigated. According to that study, the most important goal of the reporting system was to play an educational role for healthcare workers, administrators, and other health related institutions (i.e., pharmaceutical companies) and to be integrated in education [45]. The capability of the error reporting system to develop a resolution process, and to make suggestions for protection from errors, is important for the development of the best applications. For example, the corrective attempts and instruction of workers are the most important factors for the effectiveness of the error reporting system and for its adaptation by users [8]. Consequently, the basic aim of error reporting systems should be the initiation of education and corrective action.

\section{Conclusion}

Despite the fact that medical error reporting has been accepted as a basic attempt for the improvement of patient safety, error reporting barriers continue to be one of the most important healthcare problems worldwide. Since the reporting barriers determined by the literature review are similar, a common terminology that includes these barriers (similar to the classification of errors and their outcomes) could be developed. Via the development of measurement tools that include this terminology, worldwide standardization could be provided and could shed light on the attempts at proof-based reporting.

In many studies, no approaches or strategies were specified for the prevention of feelings of fear and accusation. In order to prevent a culture of fear, which is an important reporting obstacle, administrators should take charge of important responsibilities, attempts and approaches. In future studies, the reasons for a fear culture, and the suggestions of healthcare workers for changing a fear culture, could be investigated. Moreover, in light of the investigated suggestions, an improvement in reporting fear related approaches and an investigation of their results are important.

It was determined in the previously conducted studies that education provided to healthcare workers in the direction of medical error/error reporting, types and intensity of errors, and classification of errors according to patient outcomes is effective in improving the approach to error reporting. At present, technological methods present opportunities like distance training systems, simulation education, etc. and the use and investigation of these, and similar methods, is suggested to be effective on patient safety and error reporting education.

\section{Implications for Practice and Future Research}

This investigation presents up-to-date information about medical error reporting barriers, and the features of effective error reporting systems for nurse administrators, quality and risk management workers, institution administrators, and researchers. When evaluated within the scope of the investigated research questions, along with 
descriptive studies toward reporting barriers, more experimental studies are required. The constitution of error reporting systems, evaluation of its usage by healthcare workers, and sharing of the results will contribute to the literature in this field. Especially, studies that investigate the reporting barriers determined by the research and healthcare workers' suggestions, comprehensively, from a practical perspective, are thought to be beneficial.

By using the results of this review, nurse administrators could collaborate with system designers to develop effective, creative error reporting systems. At the same time, these results could contribute to the development of strategies that improve and encourage error reporting, with the aim of developing the awareness of error reporting and patient safety. The development of positive attitudes and behaviors of clinical nurses within a healthcare team, who have the potential and strength to be agents of change, would affect other team members. Accordingly, effective team cooperation, which is necessary for qualified patient care, will be provided, contributing to the leadership strength of nursing.

\section{References}

1. Marcus R (2006) Human factors in pediatric anesthesia incidents. Pediatr Anesth 16: 242-250.

2. Agency for Healthcare Research and Quality (2000) 20 Tips to help prevent medical errors 2101 East Jefferson Street. Rockville, MD.

3. Kohn LT, Corrigan JM, Donaldson MS (2000) To err is human: Building a safer health system. Institute of Medicine (US) Committee on Quality of Health Care in America, National Academies Press (US), Washington (DC).

4. John TAJ (2013) New, evidence-based estimate of patient harms associated with hospital care. J Patient Saf 9:122-128.

5. National Patient Safety Agency, National Reporting and Learning Service.

6. Page A (2004) Keeping patients safe: Transforming the work environment of nurses. The National Academies Press 500 Fifth Street, N.W. Washington, DC.

7. Pittet D, Donaldson L (2006) Challenging the world: Patient safety and health care-associated infection. Int J Qual Health Care 18: 4-8.

8. WHO (2005) Draft guidelines for adverse event reporting and learning systems from information to action. WHO/EIP/SPO/QPS/05.3 (c) World Health Organization.

9. Leigh E (2006) Great Britain Parliament House of Commons Committee of Public Accounts. A safer place for patients: Learning to improve patient safety. Fifty-first report of session 2005-06 report, together with formal minutes, oral and written evidence. London, UK: House of Commons Papers.

10. Walsh K, Burns C, Antony J (2010) Electronic adverse incident reporting in hospitals. Leadership in Health Services 23: 1751-1879.

11. Paterick ZR, Pateric JD (2009) The challenges to transparency in reporting medical errors. J Patient Saf 5: 205-209.

12. Noble DJ, Pronovost PJ (2010) Underreporting of patient safety incidents reduces health care's ability to quantify and accurately measure harm reduction. J Patient Saf 6: 247-50.

13. Karlsen KA, Hendrix TJ, O'Malley M (2009) Medical error reporting in America: A changing landscape. Qual Manag Health Care 18: 59-70.

14. Escoto KH, Karsh BT, Beasley JW (2006) Multiple user considerations and their implications in medical error reporting system design. human factors. The Journal of the Human Factors and Ergonomics Society 48: 48.

15. Kreckler S, Catchpole K, McCulloch P, Handa A (2009) Factors influencing incident reporting in surgical care. Quality Safety Health Care 18: 116-120.

16. Evans S, Berry JG, Smith BJ (2006) Attitudes and barriers to incident reporting: A collaborative hospital study. Quality Safety Health Care 15: $39-43$.
17. Hobgood C, Weiner B, Tamayo-Sarver JH (2006) Medical error identification, disclosure and reporting: do emergency medicine provider groups differ? Acad Emerg Med 13: 443-451.

18. Taylor JA, Brownstein D, Christakis DA, Blackburn S, Strandjord TP, et al. (2004) Use of incident reports by physicians and nurses to document medical errors in pediatric patients. Pediatrics 114: 729-735.

19. Lawton R, Parker D (2002) Barriers to incident reporting in a healthcare system. Quality Safety Health Care 11: 15-18.

20. Sarvadikar A, Prescott G, Williams D (2010) Attitudes to reporting medication error among differing healthcare professionals. Eur J Clin Pharmacol 66: 843-53.

21. Okuyama A, Sasaki M, Kanda K (2010) The relationship between incident reporting by nurses and safety management in hospitals. Qual Manag Health Care 19: 164-172.

22. Espin S, Griffithsb AW, Wilson M, Lingardd L (2010) To report or not to report: A descriptive study exploring ICU nurses' perceptions of error and error reporting. Intensive and Critical Care Nursing 26: 1-9.

23. Bayazidi S, Zarezadeh Y, Zamanzadeh V, Parvan K (2012) Medication error reporting rate and its barriers and facilitators among nurses. J Caring Sci 1: 231-236.

24. Mrayyan MT, Shishani K, Al-Faouri I (2007) Rate, causes and reporting of medication errors in Jordan: Nurses' perspectives. J Nurs Manag 15: 659-670.

25. Uribe CL, Schweikhart SB, Pathak DS, Dow M, Marsh GB (2002) Perceived barriers to medical-error reporting: An exploratory investigation. J Healthc Manag 47: 263-279.

26. McArdle D, Burns N, Ireland A (2003) Attitudes and beliefs of doctors towards medication error reporting. Int J Health Care Qual Assur 16: 326-333.

27. Waring JJ (2005) Beyond blame: Cultural barriers to medical incident reporting. Social Science and Medicine 60: 1927-35.

28. Coyle YM, Mercer SQ, Murphy-Cullen CL, Schneider GW, Hynan LS (2005) Effectiveness of a graduate medical education program for improving medical event reporting attitude and behavior. Qualityand Safety Health Care 14: 383-388.

29. Chiang HY, Pepper GA (2006) Barriers to nurses' reporting of medication administration errors in Taiwan. J Nurs Scholarsh 38: 392-399.

30. Ulanimo VM, O'Leary-Kelley C, Connolly PM (2007) Nurses' perceptions of causes of medication errors and barriers to reporting. J Nurs Care Qual 22: 28-33.

31. Martowirono K, Jansma JD, Van Luijk SJ, Wagner CA. Bijnen AB (2012) Possible solutions for barriers in incident reporting by residents. J Eval Clin Pract 18: 76-81.

32. Petrova E, Baldacchino D, Camilleri M (2010) Nurses' perceptions of medication errors in Malta. Nursing Standard 24: 41-48.

33. Almutary HH, Lewis PA, Cert CC (2012) Nurses' willingness to report medication administration errors in Saudi Arabia. Qual Manag Health Care 21: 119-126.

34. Hartnell N, MacKinnon N, Sketris I, Fleming M (2012) Identifying, understanding and overcoming barriers to medication error reporting in hospitals: a focus group study. BMJ Qual Saf 21: 361-368.

35. Wagner LM, Damianakis T, Pho L, Tourangeau A (2013) Barriers and facilitators to communicating nursing errors in long-term care settings. J Patient Saf 9: 1-7.

36. Heard GC, Sanderson PM, Thomas RD (2012) Barriers to adverse event and error reporting in anesthesia. Anesthesia Analgesia 114: 604-614.

37. Hashemi F, Nasrabadi AN, Asghari F (2012) Factors associated with reporting nursing errors in Iran: a qualitative study. BMC Nurs 18: 11-20.

38. Lederman R, Dreyfus S, Matchan J, Knott JC, Milton SK (2013) Electronic error-reporting systems: A case study into the impact on nurse reporting of medical errors. Nurse Outlook 61: 417-426. 
Citation: Ünal A, Seren S (2016) Medical Error Reporting Attitudes of Healthcare Personnel, Barriers and Solutions: A Literature Review. J Nurs Care 5: 377. doi:10.4172/2167-1168.1000377

Page 8 of 8

39. Ulanimo VM, O'Leary-Kelley C, Connolly PM (2007) Nurses' perceptions of causes of medication errors and barriers to reporting. J Nurs Care Qual 22: 28-33.

40. Kim J, An K, Kim MK, Yoon SH (2007) Nurses' perception of error reporting and patient safety culture in Korea. West J Nurs Res 29: 827-844.

41. Hwang JI, Lee SI, Park HA (2012) Barriers to the operation of patient safety incident reporting systems in Korean general hospitals. Healthc Inform Res 18: 279-286.

42. Ioannidis JP, Lau J (2001) Evidence on interventions to reduce medical errors: An overview and recommendations for future research. J Gen Intern Med 16: 325-334.
43. Milch CE, Salem DN, Pauker SG, Lundquist TG, Kumar S, Chen J (2006) Voluntary electronic reporting of medical errors and adverse events. An analysis of 92,547 reports from 26 acute care hospitals. J Gen Int Med 21: 165-170.

44. Benn J, Koutantji M, Wallace L, Spurgeon P, Rejman M, et al. (2009) Feedback from incident reporting: information and action to improve patient safety. Qual Saf Health Care 18: 11-21.

45. Karsh BT, Escoto KH, Beasley JW, Holden RJ (2006) Toward a theoretical approach to medical error reporting system research and design. Appl Ergon 37: 283-295. 